\title{
Effect of Glass Reinforced Epoxy (GRE) pipe filled with Geopolymer Materials for Piping Application: Compression Properties
}

\author{
Mohammad Firdaus Abu Hashim ${ }^{1, *}$, Mohd Mustafa Al Bakri Abdullah ${ }^{1,2}$, Che Mohd \\ Ruzaidi Ghazali ${ }^{1,2}$, Kamarudin Hussin ${ }^{1,2}$, Mohammed Binhussain ${ }^{3}$ and Mohd Firdaus \\ Omar $^{1}$ \\ ${ }^{1}$ Center of Excellence Geopolymer \& Green Technology (CeGeoGTech), School of Material \\ Engineering, Universiti Malaysia Perlis (UniMAP), Perlis Malaysia. \\ ${ }^{2}$ Faculty of Engineering Technology, Universiti Malaysia Perlis (UniMAP), Perlis, Malaysia. \\ ${ }^{3}$ King Abdul Aziz City Science \& Technology (KACST), Riyadh, Kingdom of Saudi Arabia.
}

\begin{abstract}
The aim of this paper is to achieve the highest compressive strength of glass reinforced epoxy pipe with the geopolymer filler content of weight percentage that were used in glass reinforced epoxy pipe. The samples were prepared by using the filament winding method. The effect of weight percentage of geopolymer materials in epoxy hardener was studied under mechanical testing, which is using the compression test. A series of glass reinforced epoxy pipe and glass reinforced epoxy pipe filled with $10-40$ weight percentage geopolymer filler which is white clay were prepared. The compression strength of the glass reinforced epoxy pipe filled geopolymer materials is determined using Instron Universal Testing under compression mode. It was found that compressive strength for samples with white clay geopolymer filler are much higher compare to glass reinforced epoxy pipe without geopolymer filler. Moreover, the compressive strength of glass reinforced epoxy pipe filled with white clay geopolymer filler was increased from $10 \mathrm{wt} \%$ to $30 \mathrm{wt} \%$ of geopolymer content. However, the compressive strength of glass reinforced epoxy pipe with white clay geopolymer filler suddenly decreased when added to 40 $\mathrm{wt} \%$. The results indicated that the blending of geopolymer materials in epoxy system can be obtained in this study.
\end{abstract}

\section{Introduction}

Filament winding is a type of composite manufacturing process, where a controlled amount of resin and oriented fibers are wound around a rotating mandrel and cured to produce the required composite part. It was initially used to produce pressure vessels, water and chemical tanks. The process of filament winding has evolved to be the preferred, and most cost effective method, for producing pressure retaining structures from fiber reinforced polymeric (FRP) composites such as piping and tanks for the transportation/storage of

\footnotetext{
* Corresponding author: firdaushashim88@yahoo.com
} 
fluids [1]. According to material properties combinations have been and yet being extended by the advance of the composite, which is a multiphase material that shows a proportion of the properties of the forming phase so that a better mixture of properties is achieved [2]. Filament winding also can be described as the process of winding fiber material and resin around a shape known as a mandrel to create composite product. The process of filament winding is typically used to produce circular composite products with a hollow core. The filament winding process can consume many different fibers and resins to achieve desired characteristics of the finished component.

The outstanding achievements in inorganic chemistry made through geopolymerization include mineral polymers which termed as polysiatate or geopolymers, making a great possibility to produce composite materials not only with excellent mechanical properties such as lightweight and high strength but also with ideal fire resistant, non-toxic fumes and smokes, and resisting all organic solvents [3-5]. For several years, researchers have been enthralled by the studies on geopolymers since they offer benefits regarding low energy consumption and the absence of $\mathrm{CO}_{2}$ emissions in the preparation process [6]. Geopolymers are an example of the broader class of alkali-activated binders, which also includes alkaliactivated metallurgical slag and other related materials [7]. Composites based on clay have been more widely studied since clay materials are naturally available and contribute to excellent mechanical properties of either thermoplastic or thermosets matrices [8].

In this research, GRE pipe which is diglycidyl ether of bisphenol A (DGEBA) epoxy were mixed with white clay geopolymer filler which became one of the greatest current interests in thermoset-based clay composites since it offers low cost, ease of processing, fine adhesion to many substrates, and good chemical resistance for a wide range of applications [9]. White clay and kaolin are linked with kaolinite. Kaolinite clay is one of most versatile industrial minerals which mostly used as ceramic raw material, coating and filler pigment for paper [6]. Therefore, these materials which fly ash, kaolin, and white clay has wide potential to be used as a source material to react with liquid alkaline activator within sodium silicate solution $\left(\mathrm{Na}_{2} \mathrm{SiO}_{3}\right)$ and sodium hydroxide $(\mathrm{NaOH})$ mixture [10].

\section{Material and Experimental Details}

Materials. The epoxy resin used was Diglycidyl Ether of Bisphenol-A (DGEBA) supplied by Euro Pharma Sdn Bhd and hardener Isophorondiamine (IPDA) was obtained from Dr Rahmatullah Holdings. The raw materials geopolymer filler was produced by Saudi local based materials. Saudi local based material which is White Clay was used in preparation of geopolymer. Geopolymer paste is formed by alkaline activator to induce the silicon and aluminum atoms in the material [11]. An alkaline activator liquid used in this research is a combination of sodium hydroxide $(\mathrm{NaOH})$ with 4 Molar and sodium silicate $\left(\mathrm{Na}_{2} \mathrm{SiO}_{3}\right)$.

Table 1. Geopolymer Formulation Design.

\begin{tabular}{|c|c|c|c|c|}
\hline Ratio=1 & \multicolumn{3}{|c|}{ Total weight } \\
\hline Material & Material (g) & \multicolumn{3}{|c|}{ Alkaline Activator (g) } \\
\hline & & $\mathbf{N a}_{\mathbf{2}} \mathbf{S i O}_{\mathbf{3}}$ & & Molarity \\
\cline { 3 - 5 } $\begin{array}{c}\text { White } \\
\text { Clay }\end{array}$ & 400 & 200 & 200 & $4 \mathrm{M}$ \\
\hline
\end{tabular}

Alkaline activator was prepared by mixing $\mathrm{NaOH}$ and sodium silicate before mixed with raw materials to increase the reactivity of solution with concentration $4 \mathrm{M}$ of $\mathrm{NaOH}$ to 
find the optimum concentration. The ratio of raw materials to alkaline activator and sodium silicate to $\mathrm{NaOH}$ is 1 . The geopolymer pastes then were cured in oven for 24 hours to 48 hours at $60^{\circ} \mathrm{C}-80^{\circ} \mathrm{C}$ and were taken out to be crushed by using ring mill. Crushed geopolymer filler were sieved using sieve size $150 \mu \mathrm{m}$.

Experimental procedure. The Epoxy Geopolymer was prepared according to the epoxy geopolymer of formulation in the Table 2 below by mechanical mixer using blade stirrer. The obtained mixing epoxy geopolymer were cured with cycloaliphatic amine curing agent IPDA. Epoxy and geopolymer materials were mixed for about 2 hours to make it completely homogeneous and followed by curing agent/hardener for about 5 minutes. After mixing epoxy hardener with geopolymer, the resin is then poured into the resin tank.

Continuous glass fibers (E Type) were impregnated ("wet-out") with geopolymeric resin by means of homemade "impregnation machine" as filament winding technique. The velocity of the fiber during the impregnation process was chosen based on the best penetration on geopolymer resin into the fibers [12]. The winding speed is controlled to generate the desired winding angle patterns. The velocity of the fiber feeding in the resin tank will depend on the mandrel rotational speed. This will be selected based on the best impregnation of geopolymer resin into the fibers.

After the appropriate number of layers has been applied according to fully wounded, filament winding samples were allowed to be cured at the mandrel in the room temperature for 1 day. After the curing process, the sample was ready to test. In order to determine the mechanical properties, several tests are performed on composite structure such as compressive test and elasticity modulus.

Table 2. Epoxy Geopolymer Formulation Design.

\begin{tabular}{|c|c|c|}
\hline $\begin{array}{c}\text { Geopolymer Materials } \\
(4 \mathbf{M})\end{array}$ & Epoxy + Hardener (\%) & Geopolymer (\%) \\
\hline \multirow{3}{*}{ White Clay } & 100 & 0 \\
\cline { 2 - 3 } & 90 & 10 \\
\cline { 2 - 3 } & 80 & 20 \\
\cline { 2 - 3 } & 70 & 30 \\
\hline
\end{tabular}

\section{Result and discussion}

\subsection{Compression}

Compression test was performed according to the ASTM D3410 using Instron Universal Testing Machine. The compression test consists of deforming a cylindrical hollow specimen to produce a thinner cylinder hollow of large diameter. The compression test is a convenient method for determining stress strain response. It may be suitable to use the compression test because the specimen is easy to make and does not need a large amount of materials. In this section, the compressive test results for the entire sample present in three major categorized according to the compression properties. There were compressive strength, compressive strain and modulus. Every compression properties show the performance of the sample.

Figure 1 below is shown the typical curves from the compression strength tests for epoxy hardener and epoxy hardener filled with $10 \mathrm{wt} \%$ - $40 \mathrm{wt} \%$ of white clay geopolymer filler. It is clearly indicated that epoxy with $30 \mathrm{wt} \%$ of white clay geopolymer filler shows the highest compression strength compare to others composition and geopolymer filler. Compression strength of the epoxy hardener filled with geopolymer filler of white clay are found to be exciting when increased slightly with the addition of up to $20 \mathrm{wt} \%$ and $30 \mathrm{wt} \%$ 
of geopolymer materials and it was supported by the rule of mixture theorem given that the addition of micro particles offer greater stiffness than epoxy matrix [13]. However, further increase of geopolymer filler loading at $40 \mathrm{wt} \%$ of white clay resulted in a slight decrease of about $2 \%$ in strength; this may be due to smaller agglomerated and disordered nature of clay.

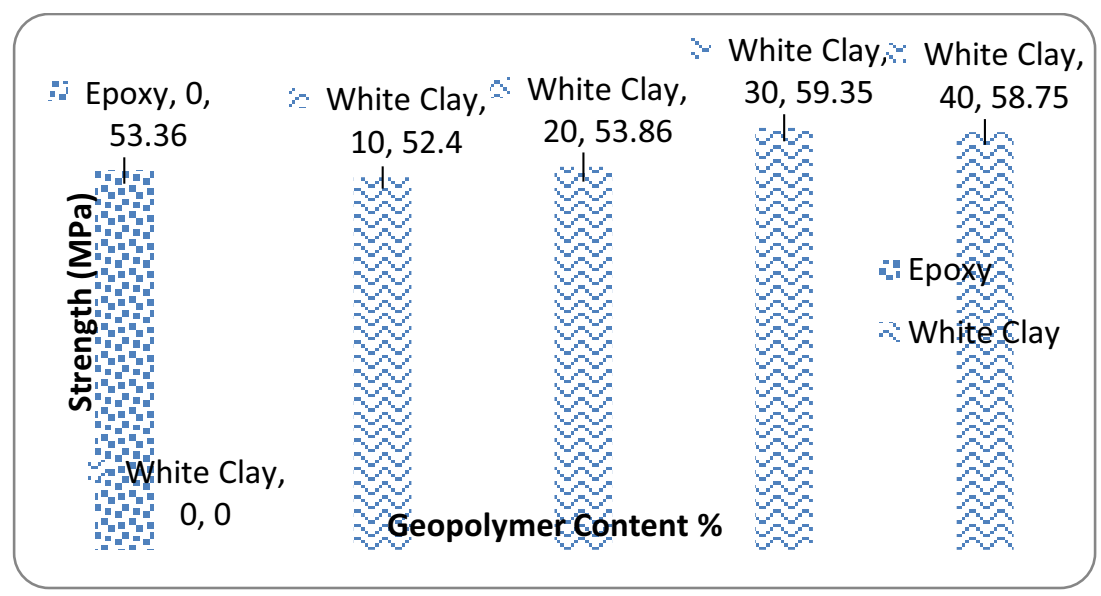

Fig. 1. Compressive Strength of Epoxy Geopolymer $0 \mathrm{wt} \%$ - $40 \mathrm{wt} \%$.

The compression properties of GRE pipe filled with geopolymer were observed from the optimum loading of geopolymer filler at $30 \mathrm{wt} \%$ of the geopolymer filler loading for 4 $\mathrm{M}$ white clay geopolymer filler, which contributed to enhancements in the interfacial bonding between the filler and the matrix, thus increasing the surface area of matrix and filler interaction. This leads to a good stress transfer from the matrix to the micro-filler, thus resulting in improved compressive strength [14]. Compressive modulus of stiffness materials in the static bending condition is tabulated in table 3 . It can be seen that the addition of epoxy-based geopolymer filler decreased from $0 \mathrm{wt} \%$ of geopolymer filler to 10 $\mathrm{wt} \%$ but tend to increase the modulus elasticity respectively.

Table 3. Compression Properties of Epoxy Hardener and Epoxy Geopolymer.

\begin{tabular}{|c|c|c|c|c|c|c|c|c|c|c|c|c|}
\hline \multicolumn{3}{|c|}{ Compressive Strength (MPa) } & \multicolumn{3}{c|}{ Compressive Strain (\%) } & \multicolumn{5}{c|}{ Modulus Elasticity (MPa) } \\
\hline & $\mathbf{1 0}$ & $\mathbf{2 0}$ & $\mathbf{3 0}$ & $\mathbf{4 0}$ & $\mathbf{1 0}$ & $\mathbf{2 0}$ & $\mathbf{3 0}$ & $\mathbf{4 0}$ & $\mathbf{1 0}$ & $\mathbf{2 0}$ & $\mathbf{3 0}$ & $\mathbf{4 0}$ \\
\hline Epoxy & \multicolumn{3}{|c|}{53.36} & \multicolumn{3}{|c|}{0.04} & \multicolumn{5}{c|}{1681.28} \\
\hline $\begin{array}{c}\text { White } \\
\text { Clay }\end{array}$ & 52.40 & 53.86 & 59.35 & 58.75 & 0.09 & 0.07 & 0.06 & 0.06 & 1008.82 & 1290.72 & 1240.95 & 1236.88 \\
\hline
\end{tabular}

\section{Conclusion}

In this study, it was found that geopolymer composite can be as a filler in the piping system application through filament winding technique that not only environmentally product but also can be ease the production cost of the product. Glass Reinforced Epoxy (GRE) pipe filled with white clay based-geopolymer was developed on epoxy resin with different weight percentage of the geopolymer material. The experimental result shows the performance of the product through the compression test. Based on the results of the 
compression test, the product from white clay with $30 \mathrm{wt} \%$ shows the highest strength compare to the others. While on the $10 \mathrm{wt} \%$ of geopolymer filler show the lowest strength even compare with GRE without geopolymer filler. Due to the good properties of the waste materials based geopolymer has bigger potential to be a matrix filler of composite with glass fiber in filament winding technique.

We would like to extend our appreciation to the Center of Excellence Geopolymer \& Green Technology (CEGeoGTech), King Abdulaziz City for Science and Technology (KACST) and all the people who helped to ensure that the successful completion of this study.

\section{References}

1. P. Mertiny, F. Ellyin., Composites, Part A, 33 (2002)

2. P. Karpuz, Middle East Technical University (2005)

3. J. Davidovits, Franca: Institut Geopolymere (2008)

4. J. Davidovits, , Proceedings of 2005 Geopolymer Conference. (2005)

5. L. Sheppar, Proceedings of the $105^{\text {th }}$. (2009)

6. $\quad$ M. Wang, D.P. H Jia, , and Y. Zhou., Mater. Lett., 64 (2010)

7. $\quad$ Z. S Yunsheng,. C.Wei, Qianli, and C. Lin., J. Hazard. Mater., 143 (2007)

8. $\quad$ M. Alexandre, P. Dubois., Mater. Sci. Eng., 28 (2000)

9. Rattanasak, U.P. Chindaprasirt., Miner. Eng., 22 (2009)

10. J. Temuujin, A.V. Riessen, K. MacKenzie, Constr. Build. Mater., 24 (2010)

11. D. Tran, D. Kroisová, P. Louda, O. Bortnovsky, P. Bezucha., Manuf. Eng. Mater. Process., 37 (2009)

12. D. Tran, P. Louda, O. Bortnovsky, P. Bezucha, The 2nd RMUTP International Conference Green Technology and Productivity (2010)

13. B. Nuhiji, D. Attard, G. Thorogood, T. Hanley, K. Magniez, J. Bungur, B. Fox., Materials, 6 (2013)

14. H. Alamri, I.M. Low, Mater. Des., 42 (2012) 